\title{
Small airway dysfunction in patients with cough variant asthma: a retrospective cohort study
}

\author{
Jie $\mathrm{GaO}^{\dagger}$, Haigui $\mathrm{Wu}^{\dagger}$ and Feng $\mathrm{Wu}^{*}{ }^{\circledR}$
}

\begin{abstract}
Background: Cough variant asthma (CVA) is one of the special populations of asthma. The aim of the study was to compare small airways, the degree of bronchial hyperresponsiveness (BHR) and airway inflammatory subtypes between CVA and classic asthma (CA), and investigate the relationship between these markers to determine the accuracy as indicators of CVA.
\end{abstract}

Methods: A total of 825 asthmatic patients participated in the study and 614 were included. 614 patients underwent spirometry and a bronchial challenge with methacholine and 459 patients performed induction sputum cell test.

Results: The number of CVA patients showed less small airway dysfunction than those of CA patients $(p<0.005)$. The degree of small airways dysfunction was higher in the CA group compared with the CVA group $(p<0.001)$. Small airways dysfunction was severer in the eosinophilic airway inflammatory subtype compared with other subtypes $(p<0.05)$. The area under curve of $\mathrm{MMEF}_{1} \mathrm{FEF}_{50}$ and $\mathrm{FEF}_{75}$ (\% predicted) was $0.615,0.621,0.606$, respectively. $0.17 \mathrm{mcg}$ of $\mathrm{PD}_{20}$ and $4.7 \%$ of sputum eosinophils was the best diagnostic value for CVA with an AUC of 0.582 and 0.575 $(p=0.001$ and $p=0.005$, respectively).

Conclusions: The eosinophilic airway inflammatory subtype may be increased small airway dysfunction. The value of small airways, BHR and induction sputum cells in CVA prediction, which reflected significant, but not enough to be clinically useful.

Keywords: Sputum cells, Bronchial hyper-responsiveness, Cough variant asthma, Classic asthma

\section{Background}

Asthma is a heterogeneous disorder disease with chronic airway inflammation of bronchial hyperresponsiveness (BHR) to a variety of stimuli, and variable expiratory airflow limitation that is often reversible either spontaneously or as a result of therapy [1,2]. "Classic asthma (CA)" is based on the characteristics and the respiratory

\footnotetext{
${ }^{*}$ Correspondence: huizhouwufeng@126.com

${ }^{\dagger}$ Jie Gao and Haigui Wu contributed equally to this work and should be considered co first authors

Department of Pulmonary and Critical Care Medicine, Huizhou the Third People's Hospital, Guangzhou Medical College, 1\# Xuebei Ave., Huizhou 516002, Guangdong, China
}

symptoms, such as shortness of breath tightness, wheeze and cough [1].

The original definition of cough variant asthma (CVA) was described by Glauser and later by Carrao, McFadden in 1972 and 1975, 1979 [3-5]. They described cough as asthmatic patient sole presenting symptom, and the symptom improved with bronchodilators alone. The European and American guidelines do not discuss specific diagnostic criteria of CVA, but they recommend that the CVA diagnosis should be determined according to the value of BHR and the therapeutic response [1]. The Chinese Cough guidelines (2016) take the detailed diagnostic criteria and treatment of CVA, which is the 
BHR and successful treatment of bronchodilators and/or inhaled corticosteroids as the basic diagnostic criteria [6].

Small airways were defined as the bronchial less than $2 \mathrm{~mm}$ in internal diameter [7]. They played a role in the pathobiology of asthma and have a distinct role in specific disease phenotypes, although they are involved in half of all cases of asthma [8-10]. The severity of asthma was also associated with inflammatory changes and functional alterations in the small airways [11, 12]. Sputum induction (inhalation hypertonic saline) is a noninvasive technique that has been valid for studying inflammatory cells in airways. In particular, sequential inductions performed after short intervals of time (20-30 min), may provide useful information on distal airway inflammation $[13,14]$. The role of the small airways in asthma is increasingly recognized as a potential target in optimal control of the disease. Therefore, this study aims to explore the validity of small airways, the degree of BHR and airway inflammatory subtypes in the diagnosis of CVA.

\section{Methods}

Study design

This retrospective study was conducted in the Huizhou Third People's Hospital of Guangzhou Medical University between January 2018 and April 2019 in China. The primary diagnosis included history inquiring and physical examination, spirometry, a bronchial challenge with methacholine, sputum induction and $\mathrm{CT}$ of the chest. The final diagnosis was made based on clinical manifestation, examination findings and a positive response to therapy. No prospective data was collected and all data was obtained retrospectively (from the hospital medical records).

CA patients were diagnosed according to (1) a clinical record of recurrent dyspnea or/and cough episodes, wheezing, chest tightness; (2) variable airflow limitation employed by BHR test or bronchodilator reversibility test; (3) a positive therapeutic response; (4) diagnosis of $\mathrm{CA}$ requires all the three points, which satisfied those of the Chinese National Guidelines on Diagnosis and Management of Asthma (2016) [15].

CVA patients were described (1) chronic cough (lasting more than 8 weeks without specific cause) as the only symptom; (2) the cough was mainly nocturnal and usually dry or productive with minimal amounts of clear sputum; (3) Normal baseline lung function, some might include small airways dysfunction; (4) a positive test for (direct) BHR; (5) No other cause of chronic cough; (6) a positive therapeutic response [6].

Inclusion criteria were: age greater than 14 years old; diagnosis of CA and CVA according to the guidelines criteria of China $[6,15]$; uncontrolled in the stage; no other apparent causes of cough; not used any corticosteroid (ICS) in the previous 4 weeks.

Exclusion criteria were: a history of COPD or asthmaCOPD overlap (ACO), bronchitis, bronchiectasis, lung cancer, cystic fibrosisor pneumonia; patients with upper airway cough syndrome (UACS), eosinophilic bronchitis (EB) and gastroesophageal reflux-related cough (GERC) [6]; do not continue treatment because of some reasons or diagnosed as other diseases after treatment.

\section{Ethics statement}

The study was conducted in accordance with the Declaration of Helsinki, and the protocol was approved by the Ethics Committee of the Huizhou third people's Hospital, which absolved the need for written informed consent because of the retrospective study. The ethics protocol number is Nov.46 [2017]. All personal identification data were anonymized and de-identified before analysis.

\section{Assessments and spirometry}

Spirometry, bronchial challenge with methacholine, induced sputum cell differentials and CT of the chest were performed on the same day. Clinical variables were recorded for the patients.

Pre-challenge spirometry: spirometry was performed by Lung Function Machine (MS-pneumo+aps; JAEGER; German). The spirometer measures lung volumes indirectly with a pneumotachograph using the pressure difference by a fine metal mesh. It is sensitive to temperature, humidity and atmospheric pressure of surrounding air and requires constant calibration every day. According to the recommendations of the Chinese National Guidelines of Pulmonary Function Test (2014): the quality and criteria of spirometry, which characteristics of rapid rise in flow/volume curve, duration of expiration more than or equal to $6 \mathrm{~s}$ and visualization of peak expiratory flow (PEF) were required. Repeat at least three times (in a reproducible way) and the best was retained. It has been estimated that less than $65 \%$ of the small airways must be obstructed before changes can be detected using routine spirometry [16, 17].

BHR test: variable airflow limitation was performed by bronchial challenge with methacholine test and the best spirometric value was measured prior to the methacholine challenge. Patients with a percentage of the predicted forced expiratory volume in first second $\left(\mathrm{FEV}_{1} \%\right.$ pred $) \geq 60 \%$ continued with the challenge (at baseline). The breath dosimeter method was used. The test sequence included five steps: $0.9 \% \mathrm{NaCl}$ only, 0.078 , $0.312,1.125$ and $2.504 \mathrm{mcg}$. Measure the $\mathrm{FEV}_{1}$ at about $60 \mathrm{~s}$ from the start of one to the start on the next inhalation from the nebulizer. Obtain an acceptable-quality $\mathrm{FEV}_{1}$ at each time point. The procedure was terminated 
when the $\mathrm{FEV}_{1}$ level fell below $20 \%$ of the baseline value. The positive response was defined as $\mathrm{PD}_{20} \leq 2.504 \mathrm{mcg}$ (between NS and $2.504 \mathrm{mcg}$ ). The cumulative dose of $\mathrm{PD}_{20}$ was used to assess the degree of BHR $[16,17]$.

Sputum samples: sputum was induced by single $3 \%$ hypertonic saline inhalation through ultrasonic atomizer for $30 \mathrm{~min}$ in total. During inhalation, patients were encouraged to stop every $10 \mathrm{~min}$ to blow their nose and rinse their mouth, then cough deeply and expectorate sputum into a sterile container. Collected lower respiratory sputum portions were dispersed using $0.1 \%$ dithiothreitol with water bath $\left(37^{\circ} \mathrm{C}\right)$ and oscillator at $15 \mathrm{~min}$ before 300 mesh nylon mesh filter. Total cell counts were centrifuged, smeared and stained (HematoxylinEosin). A differential cell counts were obtained from 400 cells with $400 \times$ microscope to identify the phenotypes of airway inflammation. We defined sputum eosinophilia $\geq 2.5 \%[6]$.

\section{Statistical analysis}

All statistical variables were analyzed using SPSS version 22 (IBM Corporation, Armonk, NY, USA). Data were presented as mean \pm standard deviation (SD) and percentages. A Student's $t$-test or Chi-square test was used to observe two groups of CVA and CA patients. Multivariate analysis of variance and analysis of covariance was used to detect the effect on the dependent variable. The relationship between small airways, $\mathrm{PD}_{20}$ and sputum cells was detected with the Person correlation coefficient. A $p$ value $<0.05$ was considered statistically significant.

\section{Results}

A total of 825 asthmatic outpatients attended the diagnosis by pulmonary and critical care medicine physicians based on clinical manifestation, examination findings and a positive response to therapy.

614 asthmatic patients were eligible and analyzed. Reasons for exclusion were (1) aged $<14$ years $(n=53)$; (2) combined diagnosis of COPD or ACO $(n=8$ and $n=5$, respectively); (3) prior diagnosis of CA or CVA $(n=67)$; (4) performed by bronchodilator reversibility test $(n=78)$ or (5) no induction sputum $(n=155)$. The strategies of the flow chart are illustrated in Fig. 1.

Demographic parameters of the included patients are presented in Table 1. Significant but weaker differences were found in the sex ratio between CVA and CA patients $(p=0.041)$. According to the results of spirometry, $\mathrm{FEV}_{1} \%$ predicted, $\mathrm{FEV}_{1}$ / forced expiratory vital capacity $(\mathrm{FVC})\left(\mathrm{FEV}_{1} / \mathrm{FVC}\right)$ and $\mathrm{PEF} \%$ predicted were higher in CVA compared to CA $(p<0.05)$. We did not find any difference in age, BMI and history of smoking between the two groups.

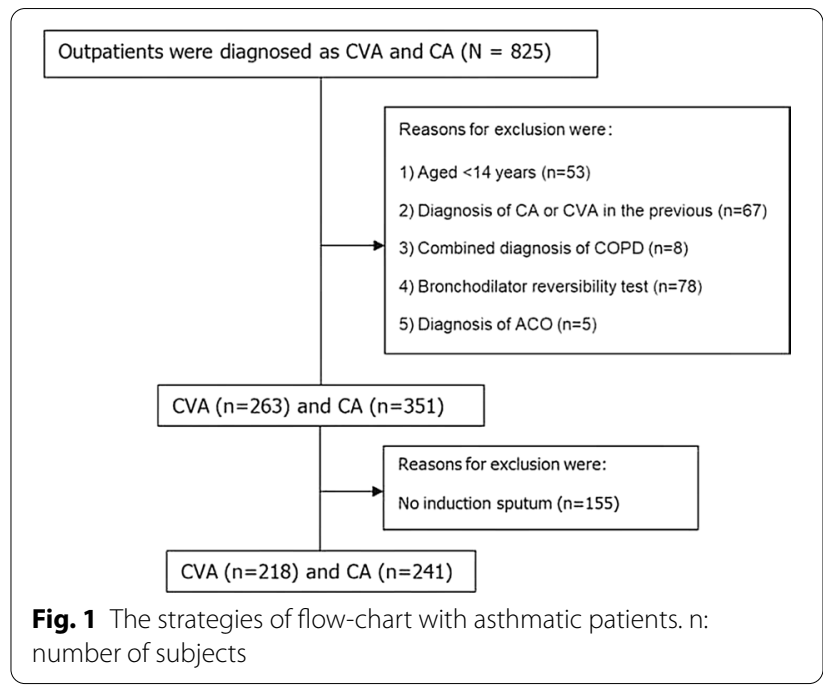

Table 1 Baseline characteristics, pre-challenge spirometry and sputum cells of patients with CVA and CA

\begin{tabular}{|c|c|c|c|}
\hline Demographic parameter & CVA & CA & $p$ \\
\hline $\mathrm{n}$ & 263 & 351 & - \\
\hline Age, years & $46.06 \pm 16.43$ & $48.64 \pm 15.85$ & 0.051 \\
\hline Females, n (\%) & $164,(62.36 \%)$ & 190, (54.13\%) & 0.041 \\
\hline $\mathrm{BMI}, \mathrm{kg} / \mathrm{m}^{2}$ & $23.54 \pm 3.62$ & $23.50 \pm 3.56$ & 0.902 \\
\hline Smokers, n (\%) & $56,(21.29 \%)$ & $95,(27.07 \%)$ & 0.100 \\
\hline FVC\% predicted & $97.55(13.48)$ & $96.47(12.92)$ & 0.317 \\
\hline $\mathrm{FEV}_{1}(\mathrm{~L})$ & $2.41(0.65)$ & $2.29(0.63)$ & 0.023 \\
\hline $\mathrm{FEV}_{1} \%$ predicted & $89.21(11.84)$ & $85.02(12.36)$ & $<0.001$ \\
\hline $\mathrm{FEV}_{1} / \mathrm{FVC}(\%)$ & $76.46(8.62)$ & $73.12(9.77)$ & $<0.001$ \\
\hline PEF\% predicted & $89.89(15.15)$ & $87.10(16.75)$ & 0.028 \\
\hline MMEF\% predicted (<65\%), n (\%) & $184(70 \%)$ & 284 (80.91\%) & 0.002 \\
\hline $\mathrm{FEF}_{50 \%}$ predicted $(<65 \%), \mathrm{n}(\%)$ & $165(62.74 \%)$ & $258(73.5 \%)$ & 0.004 \\
\hline $\mathrm{FEF}_{75 \%}$ predicted $(<65 \%), \mathrm{n}(\%)$ & $199(75.67 \%)$ & $277(78.92 \%)$ & 0.379 \\
\hline MMEF\% predicted & $56.10(18.26)$ & $49.52(19.57)$ & $<0.001$ \\
\hline $\mathrm{FEF}_{50 \%}$ predicted & $60.54(19.46)$ & $52.76(20.16)$ & $<0.001$ \\
\hline $\mathrm{FEF}_{75 \%}$ predicted & $53.37(20.18)$ & $47.10(22.92)$ & $<0.001$ \\
\hline $\mathrm{PD}_{20}(\mathrm{mcg})$ & $0.89(0.79)$ & $0.71(0.8)$ & 0.005 \\
\hline FEV 1 fall (\%) & $26.95(7.92)$ & $29.65(11.48)$ & 0.001 \\
\hline$n$ & 241 & 218 & - \\
\hline Sputum eosinophils, \% & $9.32 \pm 14.37$ & $13.57 \pm 19.76$ & 0.009 \\
\hline Sputum neutrophils, \% & $74.56 \pm 20.45$ & $69.25 \pm 22.89$ & 0.008 \\
\hline
\end{tabular}

$\mathrm{N}$ refers to the total patients; $\mathrm{n}$ refers to the sub-group population; Data are presented as mean $\pm \mathrm{SD}$ (standard deviation) and frequencies

$\mathrm{CVA}$, cough variant asthma; $\mathrm{CA}$, classic asthma; $\mathrm{BMI}$, body mass index; FVC, forced vital capacity; $F_{E V}$, forced expiratory volume in 1 second; $P E F$, peak expiratory flow; MMEF, maximum mid-expiratory flow; FEF, forced expiratory flow; $\mathrm{PD}_{20}$, fall of $\mathrm{FEV}$ by $20 \%$ of pre-challenge value; the difference between groups was analyzed by Student's t-test or Chi square. Significant $p$ value $<0.05$ 
Patients with CVA showed less small airway dysfunction $(<65 \%)$ than the CA group in MMEF\%predicted (70\% vs $80.91 \%, p=0.002)$ and $\mathrm{FEF}_{50 \%}$ predicted $(62.71 \%$ vs $73.5 \%, p=0.004)$. The function of small airways was significantly higher in the CVA group compared with the CA group $(p<0.001)$ (Table 1).

Response to BHR in CVA and CA are showed in Table 1. Significantly higher of BHR was found in CA patients than those in CVA patients $(p=0.005)$. Compared to CVA, CA showed more sensitivity in the degree of $\mathrm{FEV}_{1}$ fall (\%) ( $p=0.002$ and $p=0.001$, respectively).

Sputum eosinophilia was defined as $\geq 2.5 \%$ according the recommendations of China [6]. CVA or CA patients were divided into the eosinophilic airway inflammatory subtype group and the non- eosinophilic airway inflammatory subtype group. In the eosinophilic subtype of CVA or CA, patients had lower $\mathrm{PD}_{20}$ and proportion of neutrophils compare to the diseases of non-eosinophilic subtype $(p \leq 0.01)$. Small airways (MMEF\%predicted, $\mathrm{FEF}_{50 \%}$ predicted and $\mathrm{FEF}_{75 \%}$ predicted) were higher in the non-eosinophilic subtype of CA $(p<0.05)$, Proportion of sputum eosinophils were less in CVA both in eosinophilic airway inflammation of CVA and CV and in non-eosinophilic airway inflammation of CVA and CA (Table 2).

Figure 2 gives an overview of all correlations between small air ways $\left(\mathrm{MMEF} \%, \mathrm{FEF}_{50 \%}, \mathrm{FEF}_{75 \%}\right)$ and $\mathrm{PD}_{20}$, sputum eosinophils\% with CVA and CA. Significant positive correlations were observed for $\mathrm{PD}_{20}$ and $\mathrm{MMEF} \%$ predicted $(\mathrm{r}=0.282, p<0.001), \mathrm{FEF}_{50 \%}$ predicted $(\mathrm{r}=0.2522$, $p<0.001), \quad \mathrm{FEF}_{75 \%}$ predicted $(\mathrm{r}=0.2504, p<0.001) \quad$ in patients with CVA (Fig. 2a). We also found significant correlations between sputum eosinophils\% and MMEF\% predicted $(\mathrm{r}=-0.1449, \quad p=0.0244), \quad \mathrm{FEF}_{50 \%}$ predicted $(\mathrm{r}=-0.1509, p=0.0191)$ with CVA patients $(p<0.05)$ (Fig. 2c). Significant association between small airways and $\mathrm{PD}_{20}$, sputum eosinophils\% was also analyzed in CA $(p<0.05)$ (Fig. 2b, d).

The ROC curve of Table 3 and Fig. 3 presented small airways (MMEF\%, $\mathrm{FEF}_{50 \%}, \mathrm{FEF}_{75 \%}$ ), $\mathrm{PD}_{20}$ and sputum eosinophils\% as predictors to identified CVA from CA. The optimum cut-point for sputum eosinophils\% was $4.7 \%$ with an area under the curve (AUC) of 0.575 $(p=0.005)$, and the AUC of MMEF, $\mathrm{FEF}_{50}$ and $\mathrm{FEF}_{75}$ (\%predicted) was $0.615,0.621,0.606$, respectively. In addition, $0.17 \mathrm{mcg}$ of $\mathrm{PD}_{20}$ was the best diagnostic value for CVA with an AUC of $0.582(p=0.001)$. Data of sensitivity and specificity were showed in Table 3 . The AUC of $\mathrm{PD}_{20}$ combined with $\mathrm{MMEF} \%$ predicted was 0.616, and that combined with $\mathrm{MEF}_{50 \%}$ predicted and $\mathrm{MEF}_{75 \%}$ predicted was 0.625, 0.606, respectively (Fig. 4).

\section{Discussion}

The retrospective study showed that CVA patients were different with in proportion of sex, smoker, spirometry, BHR and proportion of sputum cells, compared to CA patients. Lower sputum eosinophilia, milder BHR and small airway dysfunction were showed in CVA, and the correlation between them was observed weak but significant differences. The eosinophilic airway inflammation of CA showed severer small airway dysfunction compared to the non-eosinophilic airway inflammation of CA and the eosinophilic airway inflammation of CVA, respectively. Small airways, $\mathrm{PD}_{20}$ and sputum eosinophils were poor to distinguish patients with CVA. We had also evaluated the value of $\mathrm{PD}_{20}$ combined with small airways

Table 2 Small airways, BHR and induction sputum in CVA and CA

\begin{tabular}{|c|c|c|c|c|c|c|c|c|}
\hline & \multirow{2}{*}{$\begin{array}{l}\text { CA-Sputum } \\
\text { eosinophilia }\end{array}$} & \multirow{2}{*}{$\begin{array}{l}\text { CA-Sputum } \\
\text { non- } \\
\text { eosinophilia }\end{array}$} & \multirow{2}{*}{$\begin{array}{l}\text { CVA-Sputum } \\
\text { eosinophilia }\end{array}$} & \multirow{2}{*}{$\begin{array}{l}\text { CVA-Sputum } \\
\text { non- } \\
\text { eosinophilia }\end{array}$} & \multicolumn{4}{|l|}{$p$ values } \\
\hline & & & & & $\begin{array}{l}\text { CA-SE vs } \\
\text { CA-NSE }\end{array}$ & $\begin{array}{l}\text { CVA-SE } \\
\text { vS CVA- } \\
\text { NSE }\end{array}$ & $\begin{array}{l}\text { CA-SE vs } \\
\text { CVA-SE }\end{array}$ & $\begin{array}{l}\text { CA-SNE vS } \\
\text { CVA-SNE }\end{array}$ \\
\hline $\mathrm{n}$ & 132 & 86 & 126 & 115 & & & & \\
\hline $\begin{array}{l}\text { MMEF\% pre- } \\
\text { dicted }\end{array}$ & $45.75 \pm 17.49$ & $51.14 \pm 19.00$ & $54.11 \pm 19.83$ & $55 \pm 17.22$ & 0.036 & 0.71 & $<0.001$ & 0.133 \\
\hline $\mathrm{FEF}_{50 \%}$ predicted & $49.94 \pm 18.6$ & $55.46 \pm 19.7$ & $58.08 \pm 20.12$ & $58.91 \pm 19.52$ & 0.038 & 0.748 & 0.001 & 0.22 \\
\hline $\mathrm{FEF}_{75 \%}$ predicted & $40.95 \pm 19.51$ & $47.58 \pm 21.31$ & $50.92 \pm 21.73$ & $50.25 \pm 19.60$ & 0.019 & 0.803 & $<0.001$ & 0.359 \\
\hline $\mathrm{PD}_{20}$ (mcg) & $0.46 \pm 0.66$ & $0.90 \pm 0.83$ & $0.60 \pm 0.72$ & $0.93 \pm 0.82$ & $<0.001$ & 0.001 & 0.006 & 0.802 \\
\hline $\begin{array}{l}\text { Sputum eosino- } \\
\text { phils, } \%^{\mathrm{a}}\end{array}$ & $21.81 \pm 21.72$ & $0.77 \pm 0.77$ & $17.14 \pm 16.26$ & $0.91 \pm 0.72$ & - & - & 0.048 & 0.032 \\
\hline $\begin{array}{l}\text { Sputum neutro- } \\
\text { phils, \% }{ }^{a}\end{array}$ & $61.68 \pm 23.16$ & $81.00 \pm 16.33$ & $67.44 \pm 21.54$ & $82.54 \pm 14.89$ & $<0.001$ & $<0.001$ & 0.032 & 0.442 \\
\hline
\end{tabular}

MMEF, maximum mid-expiratory flow; $F E F$, forced expiratory flow; $\mathrm{PD}_{20}$, fall of $\mathrm{FEV}{ }_{1}$ by $20 \%$ of pre-challenge value; $\mathrm{CA}-\mathrm{SE}, \mathrm{CA}-\mathrm{Sputum}$ eosinophilia; $\mathrm{CA}$-SNE, CA-Sputum non-eosinophilia; CVA-SE, CVA-Sputum eosinophilia; CVA-SNE, CVA-Sputum non-eosinophilia. Data are expressed as the mean \pm SD; the difference between groups was analyzed by Student's t-test or analysis of covariance. $p<0.05$ versus the control; ${ }^{a}$ Analysis of covariance, ages as a covariance variable. 

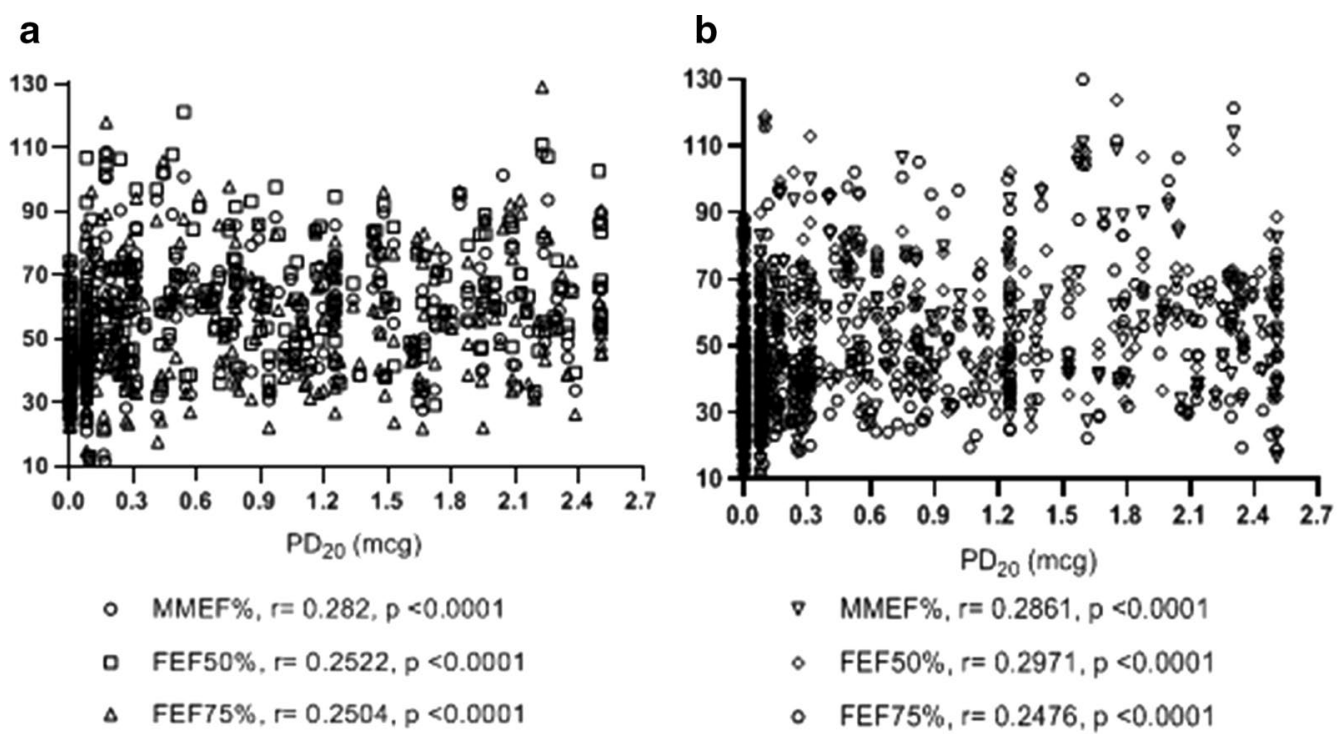

C

d
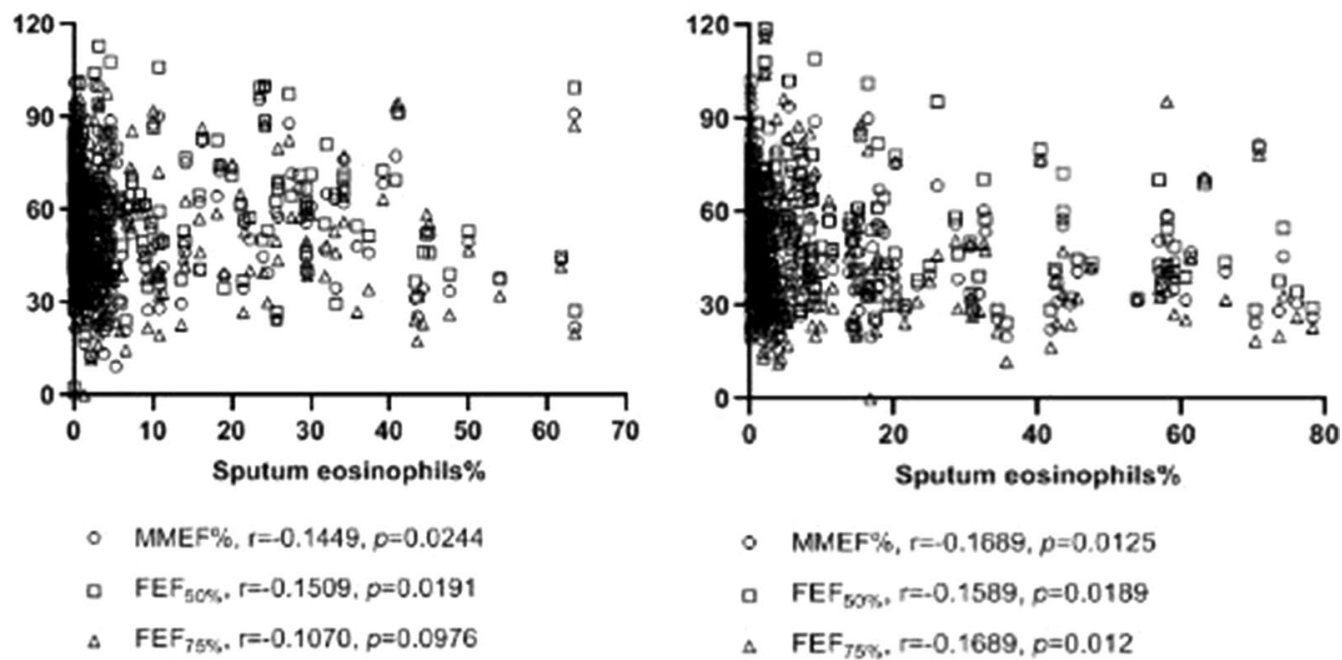

Fig. 2 Scatter plots of correlation between small airways and $\mathrm{PD}_{20}$, the percentage of sputum eosinophils. a Correlation between $\mathrm{PD}_{20}(\mathrm{mcg})$ and small airways $\left(\mathrm{MMEF} \%, \mathrm{FEF}_{50 \%}, \mathrm{FEF}_{75 \%}\right)$ in $\mathrm{CVA}$; b Correlation between $\mathrm{PD}_{20}(\mathrm{mcg})$ and small airways $\left(\mathrm{MMEF}^{2}, \mathrm{FEF}_{50 \%}\right.$, $\mathrm{FEF}_{75 \%}$ ) in CA; c Correlation between the percentage of sputum eosinophils and small airways $\left(\mathrm{MMEF}_{0}, \mathrm{FEF}_{50 \%}, \mathrm{FEF}_{75 \%}\right)$ in $\mathrm{CVA}$; $\mathbf{d}$ Correlation between the percentage of sputum eosinophils and small airways $\left(\mathrm{MMEF}_{0}, \mathrm{FEF}_{50 \%}, \mathrm{FEF}_{75 \%}\right)$ in $\mathrm{CA}$

in CVA prediction, which reflected significant, but not enough to be clinically useful.

Chronic cough is the sole presenting symptom of CVA. The chronic persistent non-productive cough is more common in females, and females are more easily troubled by the symptom $[18,19]$. The cough threshold is lower in females than in males, illustrating that the cough sensitivity is heightened in females $[20,21]$. In our study, the difference in gender is weak and the number of female was a little frequent in CVA $(p=0.041)$. Additional studies are needed to better understand gender differences.
Spirometry is the fundamental diagnostic method and is easy to assess the airflow limitation associated with asthma. Parameters such as $\mathrm{FEV}_{1}$ and PEF are frequently used to evaluate proximal airway obstruction. In the study, we found that patients with CVA have a better $\mathrm{FEV}_{1}$ predicted and PEF\%predicted $(p<0.05)$. Spirometric values indices are almost independent of the patient's activity if the expiration is forced; they depend only on the properties of the respiratory system because of the airflow limitation phenomenon [22-24]. Evaluation of forced spirometry results begins with an analysis of 
Table 3 Results of ROC analysis of $\mathrm{PD}_{\mathbf{2 0}}$ and spirometry

\begin{tabular}{|c|c|c|c|c|c|}
\hline Parameter & $\mathrm{PD}_{20}(\mathrm{mcg})$ & $\begin{array}{l}\text { Sputum } \\
\text { eosinophils\% }\end{array}$ & MMEF\% predicted & $\mathrm{FEF}_{50 \%}$ predicted & $\mathrm{FEF}_{75 \%}$ predicted \\
\hline \multicolumn{6}{|l|}{ CVA versus $C A$} \\
\hline $\operatorname{A\cup C}(95 \% \mathrm{Cl})$ & 0.582 & 0.575 & 0.615 & 0.621 & 0.606 \\
\hline Cut-off & 0.17 & 4.7 & $47.85 \%$ & $47.95 \%$ & $38.2 \%$ \\
\hline Sensitivity/specificity (\%) & $73.8 / 41.4$ & $65.7 / 52.1$ & $63.9 / 54.9$ & 73.4/48.6 & $75.7 / 43.1$ \\
\hline$p$-value & 0.001 & 0.005 & $<0.001$ & $<0.001$ & $<0.001$ \\
\hline \multicolumn{6}{|l|}{ 95\% confidence interval } \\
\hline Upper limit value & 0.627 & 0.628 & 0.659 & 0.665 & 0.649 \\
\hline Lower limit value & 0.537 & 0.523 & 0.570 & 0.577 & 0.560 \\
\hline
\end{tabular}

CVA, cough variant asthma; $C A$, classic asthma; $\mathrm{PD}_{20}$, Does of methacholine induce a $20 \%$ decrease in FEV 1 . Significant $p$ value $<0.05$.
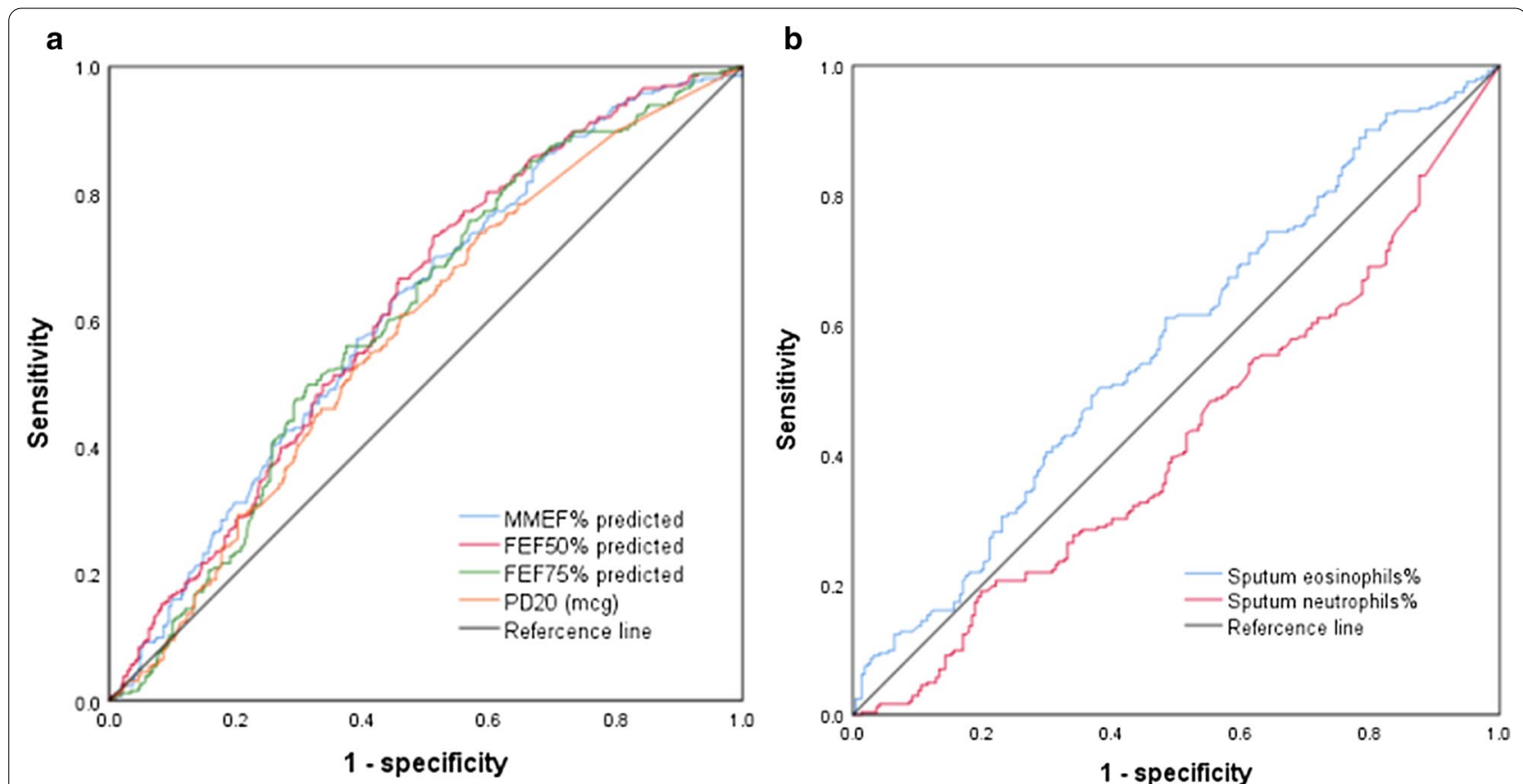

Fig. 3 ROC curve analysis for CVA versus CA. a PD $20, \mathrm{MMEF} \mathrm{FEF}_{50}, \mathrm{FEF}_{75}$ (\% predicted) or CVA diagnosis; $\boldsymbol{b}$ the percentage of sputum cells for $C V A$ diagnosis

whether bronchial airflow capacity is quantified through the FEV

Previously, asthma was understood to be a disease primarily of the central airways. However, surgical lung specimens with living chronic asthma and autopsy specimens with fatal asthma reveal mucus plugging and inflammatory involvement of both the small and large airways $[25,26]$. An inflammatory characterized by increased $\mathrm{T}$ cells, activated eosinophils and major basic protein in the small airways, which was similar to the inflammation of the central airways [26]. The intensity of the inflammation may be even higher in the small airways compared with central airways [27]. These observation confirm that the chronic inflammation of asthma involves the entire lung, from the large proximal to the small distal airways. Flow measures of small airways commonly used in forced expiratory flow at $50 \%$ $\left(\mathrm{FEF}_{50 \%}\right), 75 \%\left(\mathrm{FEF}_{75 \%}\right)$ and $25-75 \%\left(\mathrm{FEF}_{25-75 \%} / \mathrm{MMEF}\right)$ of FVC. Among these parameters, $\mathrm{FEF}_{25-75 \%}$ is the most commonly adopted, although the literature supporting its reliability is not conclusive.

The pathophysiological features of CVA are similar to those of CA. CVA shows similar levels of eosinophilic airway inflammation and a milder degree of airway remodeling, such as subepithelial thickening, goblet cell hyperplasia, and vascular proliferation [28-30]. Nearly 


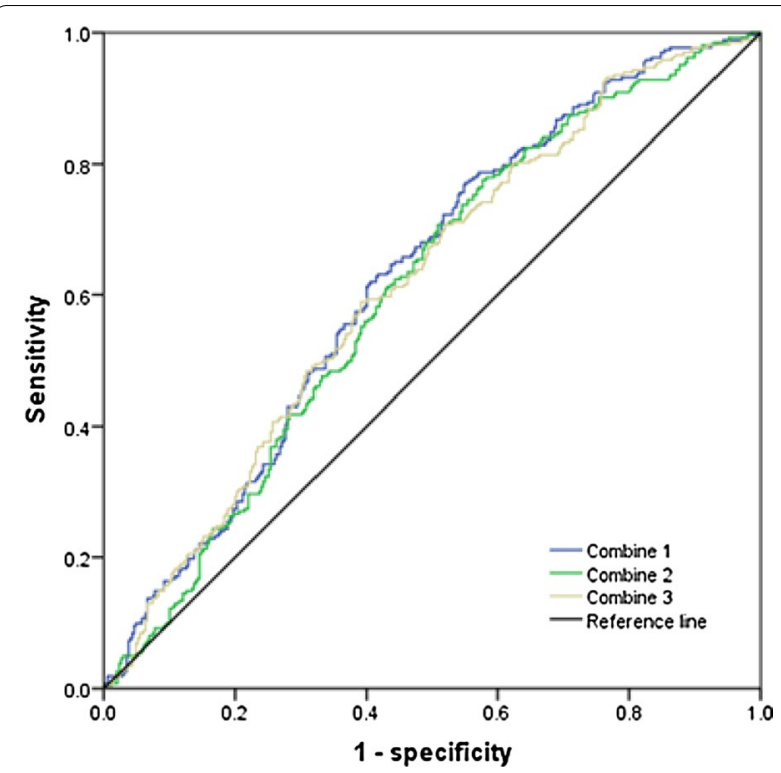

Fig. 4 Predictive value for CVA by combining $\mathrm{PD}_{20}$ and small airway resistance; combination 1: $\mathrm{PD}_{20}+\mathrm{FEF}_{50}$ (\% predicted); combination 2: $\mathrm{PD}_{20}+\mathrm{FEF}_{75}$ (\% predicted); combination 3: $\mathrm{PD}_{20}+\mathrm{MMEF}(\%$ predicted)

$30 \%$ of CVA patients eventually develop to CA, sometimes severe enough to require continuous treatment [5, 31]. Given these studies, CVA is considered to be the initial stage of asthma [32]. Therefore, early diagnosis and treatment are recommended to attenuate the inflammation and remodeling. In our study, the spirometric parameters for small airways with the CVA group were better than those with the CA group. Small airway dysfunction was present in a large proportion of asthma patients at baseline, and less in CVA compared to those of CA. The eosinophilic airway inflammation of CA showed severer small airway dysfunction. A positive relationship between small airways and $\mathrm{PD}_{20}$, induced sputum cells in both CVA and CA. The optimum cut-point for $\mathrm{MMEF}, \mathrm{FEF}_{50 \%}$ predicted and $\mathrm{FEF}_{75 \%}$ predicted were $47.85 \%, 47.79 \%$ and $38.2 \%$, and the AUC of them were $0.615,0.621$ and 0.606 , respectively. $0.17 \mathrm{mcg}$ of $\mathrm{PD}_{20}$ and $4.7 \%$ of sputum eosinophilia may help identify CVA with an AUC of 0.582 and $0.575(p=0.001$ and $p=0.005$, respectively). The correlation and ROC analyses demonstrated a relatively poor, although significant relationship for small airways, $\mathrm{PD}_{20}$ and induced sputum cells to predict CVA in statistics.

\section{Limitation of the study}

A positive relationship showed between small airways and $\mathrm{PD}_{20}$, sputum cells. However, overall the association appeared weak and low AUCs for the prediction to CVA. While these correlations might show statistical significance, none of these appear convincing and potentially clinically relevant judged. Similarly, the low AUC values are highly unreliable and not helpful to inform clinical decision making.

\section{Conclusions}

This study showed that lower sputum eosinophilia, milder small airway obstruction and BHR are in CVA. The eosinophilic airway inflammatory subtype of CA showed severer small airway dysfunction. However, the relationship between them is poor. Small airways and $\mathrm{BHR}$, induction sputum cells may not be used to detect CVA patients. Based on these weak correlations and prediction values, further investigations would be required.

\section{Abbreviations \\ BHR: Bronchial hyper-responsiveness; GINA: The Global Initiative for Asthma;

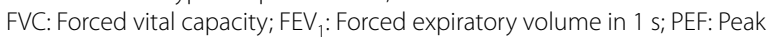 expiratory flow; MMEF: Maximum mid expiratory flow; MEF: Maximal expira- tory flow; CVA: Cough variant asthma; CA: Classic asthma.}

\section{Acknowledgements}

Not applicable.

\section{Author contributions}

GJ performed data collection and analysis, and was a major contributor in writing the manuscript. WHG analyzed and interpreted the patient data with asthma. WF analyzed and interpreted the data, and designed and supervised study. All authors read and approved the final manuscript.

\section{Funding}

Not applicable.

\section{Availability of data and materials}

Due to the institutional policy, the datasets used and/or analysed during the current study are available from the corresponding author on reasonable request.

\section{Ethics approval and consent to participate}

The study was conducted in accordance with the Declaration of Helsinki, and the protocol was approved by the Ethics Committee of Huizhou third people's Hospital, which absolved the need for written informed consent because of the retrospective study. All personal identification data were anonymized and de-identified before analysis.

\section{Consent for publication}

Not applicable.

\section{Competing interests}

The authors declare that they have no competing interests.

Received: 18 October 2020 Accepted: 27 January 2021

Published online: 03 February 2021

\section{References}

1. Global Initiative for Asthma. Global strategy for asthma management and prevention.https://ginasthma.org/pocket-guide-for-asthma-manag ement-and-prevention/. Accessed 19 April 2019.

2. Program NAEaP. Expert panel report 3 (EPR-3): guidelines for the diagnosisand management of asthma-summary report 2007. J Allergy Clin Immunol. 2007;5:S94-S138.

3. Glauser FL. Variant asthma. Ann Allergy. 1972;30:457-9. 
4. McFadden ER Jr. Exertional dyspnea and cough as preludes to acute attacks of bronchial asthma. N Engl J Med. 1975;292:555-9.

5. Corrao WM, Braman SS, Irwin RS. Chronic cough as the sole presenting manifestation of bronchialasthma. N Engl J Med. 1979;300:633-7.

6. Asthma Workgroup of Chinese Society of Respiratory Diseases (CSRD), Chinese Medical Association. The Chinese national guidelines on diagnosis and management of cough (2015). Chin J Tuberc Respir Dis. 2016;39:321-39

7. Contoli M, Bousquet J, Fabbri LM, et al. The small airways and distal lung compartment in asthma and COPD: a time for reappraisal. Allergy. 2010;65:141-51.

8. Bonini M, Usmani OS. The role of the small airways in the pathophysiology of asthma and chronic obstructive pulmonary disease. Ther Adv Respir Dis. 2015;9:281-93.

9. Farah CS, Keulers LA, Hardaker KM, et al. Association between peripheral airway function and neutrophilic inflammation in asthma. Respirology. 2015;20:975-81.

10. Contoli M, Santus P, Papi A. Small airway disease in asthma: pathophysiological and diagnostic considerations. Curr Opin Pulm Med. 2015;21:68-73.

11. Perez T, Chanez P, Dusser D, et al. Small airway impairment in moderate to severe asthmatics without significant proximal airway obstruction. Respir Med. 2013;107:1667-74

12. Alfieri V, Aiello M, Pisi R, et al. Small airway dysfunction is associated to excessive bronchoconstriction in asthmatic patients. Respir Res. 2014;15:86

13. Magnussen $\mathrm{H}$, Holz $\mathrm{O}$. Monitoring airway inflammation in asthma by induced sputum. Eur Respir J. 1999;13:5-7.

14. Thompson B, Douglass J, Ellis MJ, et al. Peripheral lung function in patients with stable and unstable asthma. J Allergy Clin Immunol. 2013;131:1322-8.

15. Asthma Workgroup of Chinese Society of Respiratory Diseases (CSRD), Chinese Medical Association. The Chinese national quidelines on diagnosis and management of asthma (2016). Chin J Tuberc Respir Dis. 2016;39:675-97.

16. Pulmonary Function Workgroup of Chinese Society of Respiratory Diseases (CSRD), Chinese Medical Association. The Chinese national guidelines of pulmonary function test (2014). Chin J Tuberc Respir Dis. 2014;37:566-71.

17. Miller MR, Hankinson J, Brusasco V, et al. ATS/ERS Task Force. Standardization of spirometry. Eur Respir J. 2005;26:319-38.

18. Fujimura M, Sakamoto S, Matsuda T. Bronchodilator-resistive cough in atopic patients: bronchial reversibility and hyperresponsiveness. Intern Med. 1992;31:447-52.
19. Fujimura M, Kamio Y, Hashimoto T, et al. Cough receptor sensitivity and bronchial responsiveness in patients with only chronic nonproductive cough in view of effect of bronchodilator therapy. J Asthma. 1994;31:463-72.

20. Fujimura $\mathrm{M}$, Kasahara $\mathrm{K}$, Kamio Y, et al. Female gender as a determinant of cough threshold to inhaled capsaicin. Eur Respir J. 1996;9:1624-6.

21. Kastelik JA, Thompson RH, Aziz I, et al. Sex-related differences in cough reflex sensitivity in patients with chronic cough. Am J Respir Crit Care Med. 2002;166:961-4.

22. Mead J, Turner JM, Macklem PT, et al. Significance of the relationship between lung recoil and maximum expiratory flow. J Appl Physiol. 1967;22:95-108.

23. Pride NB, Permutt S, Riley RL, et al. Determinants of maximal expiratory flow from the lungs. J Appl Physiol. 1967;23:646-62.

24. Golczewski T, Darowski M. Virtual respiratory system for education and research: simulation of expiratory flow limitation for spirometry. Int J Artif Organs. 2006;29:961-72.

25. Kuyper LM, Pare PD, Hogg JC, et al. Characterization of airway plugging in fatal asthma. Am J Med. 2003;115:6-11.

26. Hamid Q, Song Y, Kotsimbos TC, et al. Inflammation of small airways in asthma. J Allergy Clin Immunol. 1997;100:44-51.

27. Balzar S, Wenzel SE, Chu HW. Transbronchial biopsy as a tool to evaluate small airways in asthma. Eur Respir J. 2002;20:254-9.

28. Niimi A, Amitani R, Suzuki K, et al. Eosinophilic inflammation in cough variant asthma. Eur Respir J. 1998:11:1064-9.

29. Niimi $A$, Matsumoto $H$, Minakuchi $M$, et al. Airway remodelling in coughvariant asthma. Lancet. 2000:356:564-5.

30. Niimi A, Torrego A, Nicholson AG, et al. Nature of airway inflammation and remodeling in chronic cough. J Allergy Clin Immunol. 2005; 116:565-70.

31. Fujimura M, Nishizawa $Y$, Nishitsuji $M$, et al. Longitudinal decline in pulmonary function in atopic cough and cough variant asthma. Clin Exp Allergy. 2003:33:588-94.

32. Kang $H$, Koh $Y Y$, Yoo $Y$, et al. Maxima lairway response to methacholine in cough-variant asthma: comparison with classic asthma and its relationship to peak expiratory flow variability. Chest. 2005;128:3881-7.

\section{Publisher's Note}

Springer Nature remains neutral with regard to jurisdictional claims in published maps and institutional affiliations.
Ready to submit your research? Choose BMC and benefit from:

- fast, convenient online submission

- thorough peer review by experienced researchers in your field

- rapid publication on acceptance

- support for research data, including large and complex data types

- gold Open Access which fosters wider collaboration and increased citations

- maximum visibility for your research: over 100M website views per year

At BMC, research is always in progress.

Learn more biomedcentral.com/submissions 